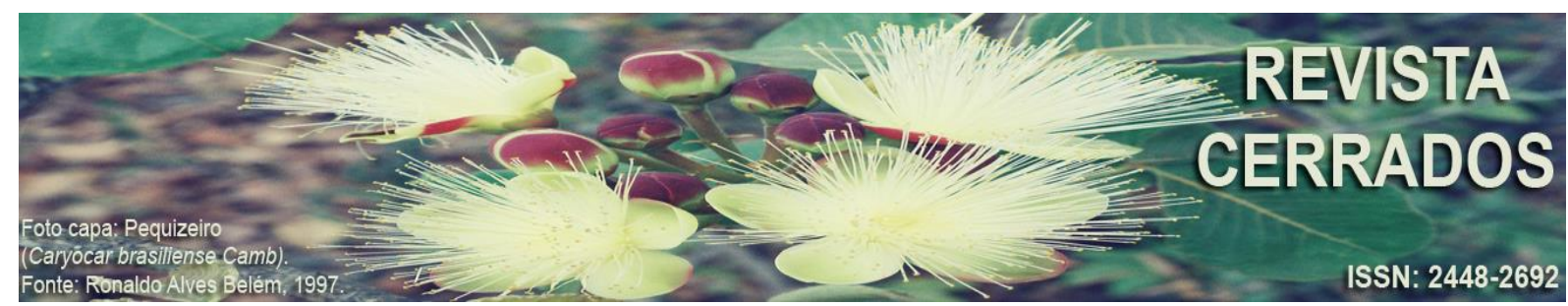

\title{
SERRA DA CONFUSÃO DO RIO PRETO (QUIRINÓPOLIS E RIO VERDE, ESTADO DE GOIÁS): trabalho de campo, investigações e ensinagens
}

\author{
SERRA DA CONFUSÃO DO RIO PRETO (QUIRINÓPOLIS AND RIO \\ VERDE, GOIÁS STATE): fieldwork, investigations and teachings
}

\section{SERRA DA CONFUSÃO DO RIO PRETO (QUIRINÓPOLIS Y RIO VERDE, ESTADO DE GOIÁS): trabajo de campo, investigaciones y enseñanzas}

\author{
Jean Carlos Vieira Santos \\ Universidade Estadual de Goiás - UEG \\ E-mail: 〈svcjean@yahoo.com.br>. \\ Vandervilson Alves Carneiro \\ Universidade Estadual de Goiás - UEG \\ E-mail: <vandervilson.carneiro@ueg.br>. \\ Pedro Oliveira Paulo \\ Universidade Estadual de Goiás - UEG \\ E-mail: <pedro.paulo@ueg.br>.
}

\begin{abstract}
Resumo
O texto realiza um levantamento da fisiografia e da geodiversidade da Serra da Confusão do Rio Preto nas áreas municipais de Quirinópolis e Rio Verde (Estado de Goiás) como aporte potencial de implementação de atividade turística em domínio rural. Para a realização do estudo, apoiou-se em levantamento bibliográfico, trabalho de campo com pesquisadores e alunos, registro fotográfico e anotações em caderneta acerca da área pesquisada. Conclui-se que a área de estudo deve receber uma atenção especial na forma de políticas públicas voltadas à atividade turística de pequena escala, respeitando e valorizando seus moradores, suas tradições e costumes, promovendo uma adequada qualidade de vida, um incremento de renda e destacando os lugarejos com sua fisiografia e geodiversidade.
\end{abstract}

Palavras-chave: Geodiversidade; Ensino de Geociências e Turismo; Espaço e cultura do mundo rural. 


\section{Abstract}

The text makes a survey of the physiography and geodiversity of the Serra do Confusão do Rio Preto in the municipal areas of Quirinópolis and Rio Verde (State of Goiás) as potential contribution of implementation of tourism activity in countryside domain. The study was supported by a bibliographical survey, fieldwork with researchers and students, photographic record and notebook notes about the researched area. It is concluded that the study area should receive special attention in the form of public policies aimed at small-scale tourism activity, respecting and valuing its residents, their traditions and customs, promoting an adequate quality of life, an increase in income and highlighting the villages with their physiography and geodiversity.

Keywords: Geodiversity; Teaching of Geosciences and Tourism; Space and culture of the countryside.

\section{Resumen}

El texto realiza un levantamiento de la fisiografía y de la geodiversidad de la Serra da Confusão do Rio Preto en las áreas municipales de Quirinópolis y Río Verde (Estado de Goiás) como aporte potencial de implementación de actividad turística en dominio rural. Para la realización del estudio, se apoyó en levantamiento bibliográfico, trabajo de campo con investigadores y alumnos, registro fotográfico y anotaciones en cuaderno acerca del área investigada. Se concluye que el área de estudio debe recibir una atención especial en la forma de políticas públicas orientadas a la actividad turística de pequeña escala, respetando y valorizando a sus habitantes, sus tradiciones y costumbres, promoviendo una adecuada calidad de vida, un incremento de renta y destacando los lugarejos con su fisiografía y geodiversidad.

Palabras llave: Geodiversidad; Enseñanza de Geociencias y Turismo; Espacio y cultura del mundo rural.

\section{INTRODUÇÃO}

Este artigo objetiva suscitar uma discussão acerca das ensinagens e investigações geográfica, geológica e paleontológica na Serra da Confusão do Rio Preto nos municípios de Quirinópolis e Rio Verde (Estado de Goiás).

As dimensões educativas e socioespaciais são abordagens que instigam diversos questionamentos: Como a educação em sítios geológicos e paleontológicos podem conquistar espaços numa região econômica marcada pelo agronegócio? Quais motivações, além do cunho educativo/investigativo são inerentes a essa paisagem? Como os sujeitos rurais se 
SANTOS, J. C. V.; CARNEIRO, V. A.; PAULO, P. O.

Serra da Confusão do Rio Preto (Quirinópolis e Rio Verde, estado de Goiás): trabalho de campo, investigações e ensinagens

relacionam com investigadores e professores que desenvolvem seus projetos na Serra da Confusão do Rio Preto?

A região Sudoeste Goiano, precisamente o município de Rio Verde, a partir da década de 1960, passa a vivenciar a modernização da agricultura, ou seja, recebe incentivos da Revolução $\operatorname{Verde}^{1}$ e, principalmente, pela intervenção do Estado por meio das políticas desenvolvimentistas (PEDROSO, 2006).

Então, com a incorporação do Cerrado na expansão da fronteira agrícola, e com a chegada da Revolução Verde, culturas agrícolas que até então não eram comuns em Rio Verde e adjacências, como é o caso da soja, foram introduzidas substituindo o antigo padrão praticado nas áreas cerradeiras: pecuária extensiva e produção de alimentos básicos (PEDROSO, 2006).

Infere-se que o município de Rio Verde e áreas adjacentes estão se fortalecendo como polo de produção agropecuária, que agregam tanto a comercialização como o processamento de insumos e os bens de produção para a agricultura, através de altíssimos investimentos agrotecnológicos.

Nas referidas áreas adjacentes, temos o município de Quirinópolis que está em uma área estrategicamente escolhida pelo capital agrário, onde:

[...] pelo seu forte potencial de elementos naturais [a Serra da Confusão do Rio Preto e sua geodiversidade], de organização e coordenação do processo produtivo, acolhendo duas agroindústrias da cana-de-açúcar para a fabricação de etanol e/ou açúcar, e também outras empresas de produção e serviços ligadas a este setor (SOUZA, 2015, p. 7).

Esse cenário do Sudoeste Goiano, onde estão os municípios de Quirinópolis e Rio Verde, propiciam conforme Leal et al. (2009, p. 11):

\begin{abstract}
Nessa época de globalização da economia o desenvolvimento no campo se torna um desafio, e para sobressair é necessário uma busca por alternativas que possam proporcionar melhores condições de vida a população rural. E como alternativa viável encontra-se o turismo no meio rural como atividade não-agrícola, propiciando emprego e renda. Ou seja, como a agropecuária não proporciona uma renda que torne possível a reprodução social dos pequenos agricultores, estes se vêem em busca de alternativas: migrarem para as grandes cidades, complementarem a renda fora da propriedade ou na própria propriedade. Essa necessidade de busca por remuneração complementar fez com que nascessem e crescesse as atividades nãoagrícolas no meio rural, um fenômeno denominado de pluriatividade.
\end{abstract}

\footnotetext{
${ }^{1} \mathrm{O}$ processo de modernização agrícola veio com o propósito de aumentar a produção através do desenvolvimento em sementes, fertilização do solo e utilização de máquinas no campo que pudessem aumentar a produção.
} 
SANTOS, J. C. V.; CARNEIRO, V. A.; PAULO, P. O.

Serra da Confusão do Rio Preto (Quirinópolis e Rio Verde, estado de Goiás): trabalho de campo, investigações e ensinagens

Nesse caminho, concorda-se que:

O turismo rural proporciona a valorização do ambiente onde é explorado por sua diversidade natural e cultural, propiciando a conservação e manutenção do patrimônio histórico, cultural e natural, contribuindo para reorganização social e econômica do local por oferecer benefícios diretos à população local que tem participação direta e indireta com as atividades ligadas ao turismo. Então, para seu total sucesso, a política de turismo rural deve ser baseada e adaptada às necessidades, possibilidades e problemas do mundo rural, especialmente da comunidade local (LEAL et al., 2009, p. 12-13).

"Afinal, o avanço tecnológico e a dinâmica [das monoculturas da cana, da soja e de outros grãos] promovem no interior do Brasil, especialmente em Goiás, mudanças substanciais nas formas, nas relações de produção e nas novas ressignificações da estrutura existente" (SANTOS et al., 2010, p. 93).

A chegada do turismo à região do Sudoeste Goiano, aproveitando-se das belezas cênicas da Serra da Confusão do Rio Preto e sua geodiversidade, poderá proporcionar aos pequenos e médios proprietários rurais, ou mesmo para as comunidades rurais, uma expectativa de desenvolvimento local e regional, pois significa a circulação de mais capital, mais empregos e grandes expectativas para lugares onde ainda são marcantes o modo de vida tradicional e que não foram apropriados pelo agronegócio (SANTOS, 2013).

Entende-se que as belezas cênicas da Serra da Confusão do Rio Preto e sua geodiversidade estão alinhadas aos propósitos do geoturismo, pois, alicerça uma prática de turismo sustentável, cujo foco principal consiste na apreciação e em estudos dos aspectos geológicos, hídricos, geomorfológicos, paleontológicos e outros, de uma maneira tal, que fomenta no seu público a compreensão cultural e ambiental e a percepção da necessidade de conservação desta fisiografia regional, conforme apregoa Dowling (2009).

\section{Breve fisiografia da Serra da Confusão do Rio Preto}

A Serra da Confusão do Rio Preto (figura 1) está localizada na região do Bioma Cerrado no interior do Brasil, especificamente na bacia hidrográfica do Rio Paranaíba. Esse bioma, também chamado de "savana brasileira" está bastante degradado, pois o agronegócio, com suas imensas lavouras tecnificadas, tem reduzido essa vegetação a pequenos espaços. Dimensão transformadora que tem comprometido a aprendizagem local, pois as práticas e posicionamentos educativos não conseguem acompanhar a rapidez de tais modificações espaciais. 


\section{Figura 1 -Visão da Serra da Confusão do Rio Preto em Quirinópolis / GO}

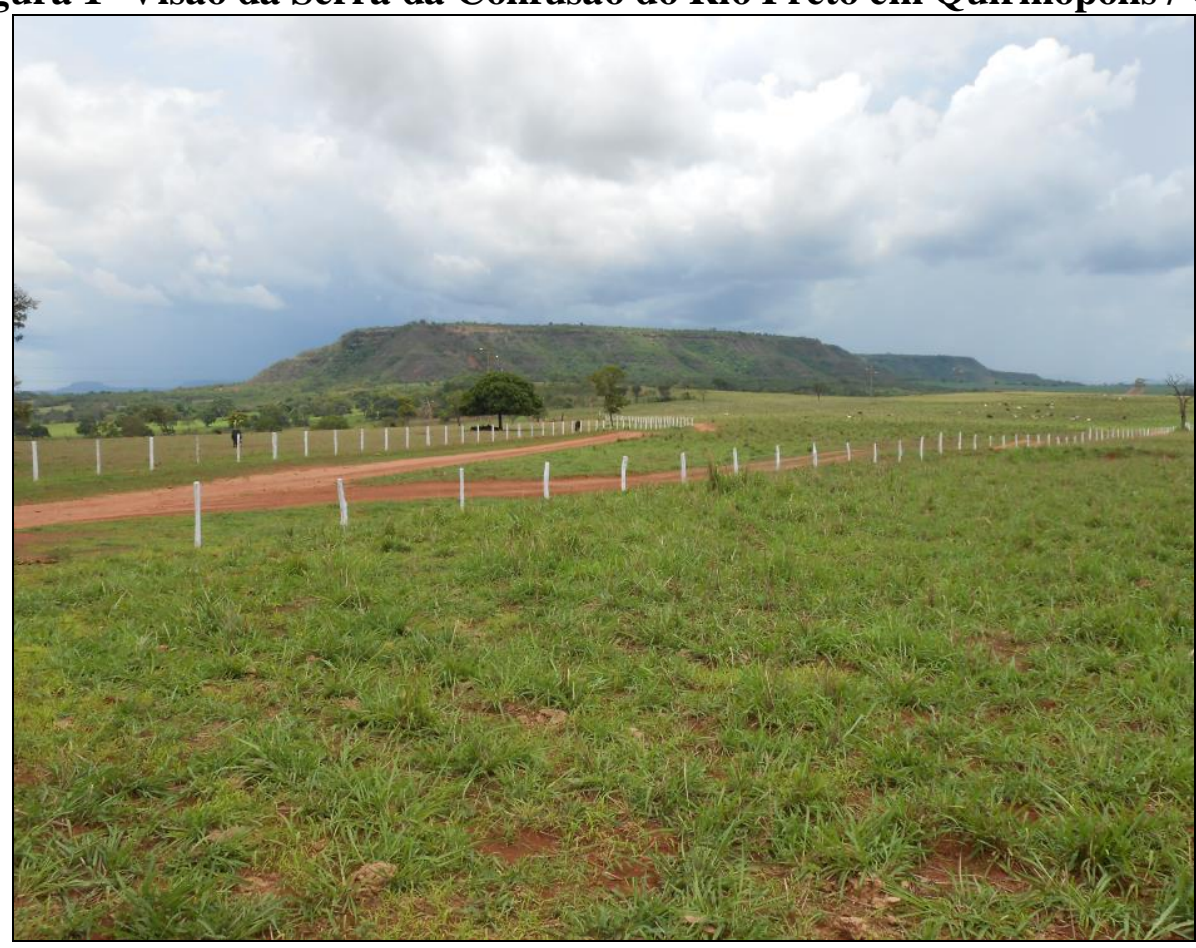

Fonte: Vandervilson Alves Carneiro (2014).

Coutinho (2009, p. 19) é incisivo ao dizer que "modernamente, o Cerrado é considerado como sendo uma savana. Este termo aceita dois conceitos: um de natureza meramente fitofisionômica e outro referente a um grande tipo de ecossistema, com seu tipo particular de vegetação". Destaca ainda que [...] "todavia, a grande maioria dos autores nacionais e internacionais, aceita o Cerrado como sendo um bioma de savana" (COUTINHO, 2006, p. 19).

O Cerrado, segundo maior bioma brasileiro, é um mosaico de formações vegetais que variam desde campos abertos até formações densas de florestas que podem atingir os trinta metros de altura (KLINK; MACHADO, 2005) (figura 2).

Aguiar e Camargo (2004, p. 17) relatam que "a cobertura arbórea e a densidade de árvores podem variar bastante entre as fisionomias, mas se observam um gradiente de valores entre as áreas campestres e as áreas florestais". Cabe inferir que a área drenada pelo Rio Paranaíba:

[...] é a segunda maior bacia da região hidrográfica do Rio Paraná com uma área de $222.767 \mathrm{~km}^{2}$. A nascente do Rio Paranaíba situa-se na Mata da Corda, no Município de Rio Paranaíba/MG, e sua bacia de captação abrange parte dos estados de Goiás, Minas Gerais, Mato Grosso do Sul e Distrito Federal (FLAUZINO et al., 2010, p. 78). 


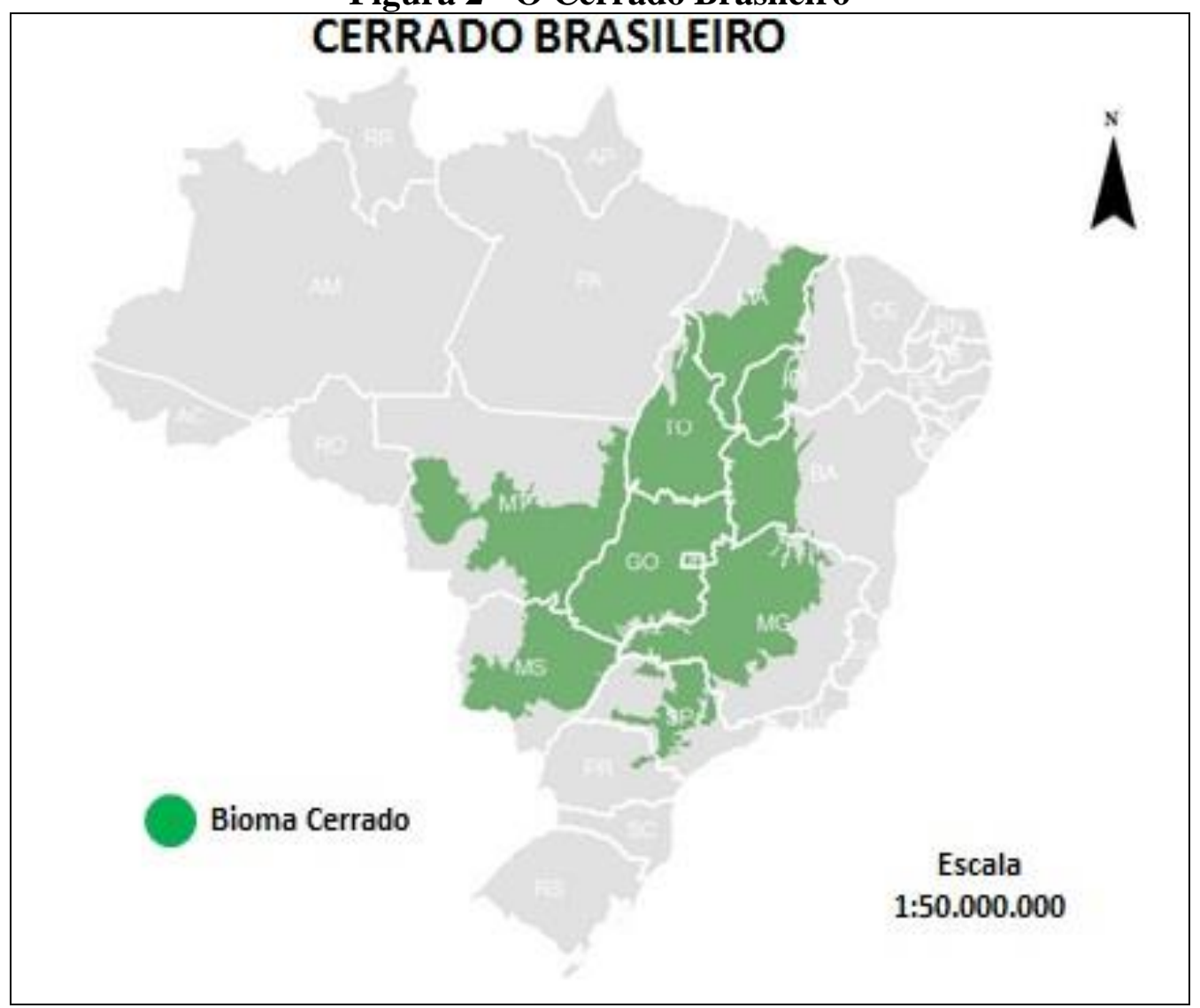

Fonte: ICS (2011), modificado por Vandervilson Alves Carneiro (2015).

Essa grande bacia do centro-sul brasileiro está inserida na unidade morfoestrutural denominada por áreas de Planaltos e Chapadas da Bacia Sedimentar do Paraná (ROSS, 1985), dentro da subunidade morfoescultural do Planalto Setentrional da Bacia do Paraná (NASCIMENTO, 1991). De acordo com a AGMA (2005)² e Santos (2013), o Rio Paranaíba nasce na Serra da Mata da Corda (Estado de Minas Gerais) a uma altitude de 1.140 metros. Dessa região até se encontrar com o Rio Grande, percorre uma extensão de $1.120 \mathrm{~km}$.

Dada à localização geográfica na bacia do Rio Paranaíba (figura 3), AGMA (2005, p. 26) e Santos (2010, p. 106) caracterizam geologicamente essa região da seguinte forma:

[...] está inserida na Bacia Sedimentar do Paraná, com uma estrutura rochosa do tipo intracratônica, constituída por uma sequência de rochas sedimentares e derrames de lavas basálticas [...]. Nesses aspectos geológicos, é possível verificar regionalmente as principais unidades litoestratigráficas, englobando importantes formações rochosas distintas.

\footnotetext{
2 antiga Agência Goiana do Meio Ambiente
} 
Figura 3 - Bacia Hidrográfica do Rio Paranaíba (GO / MG) e a área de estudo

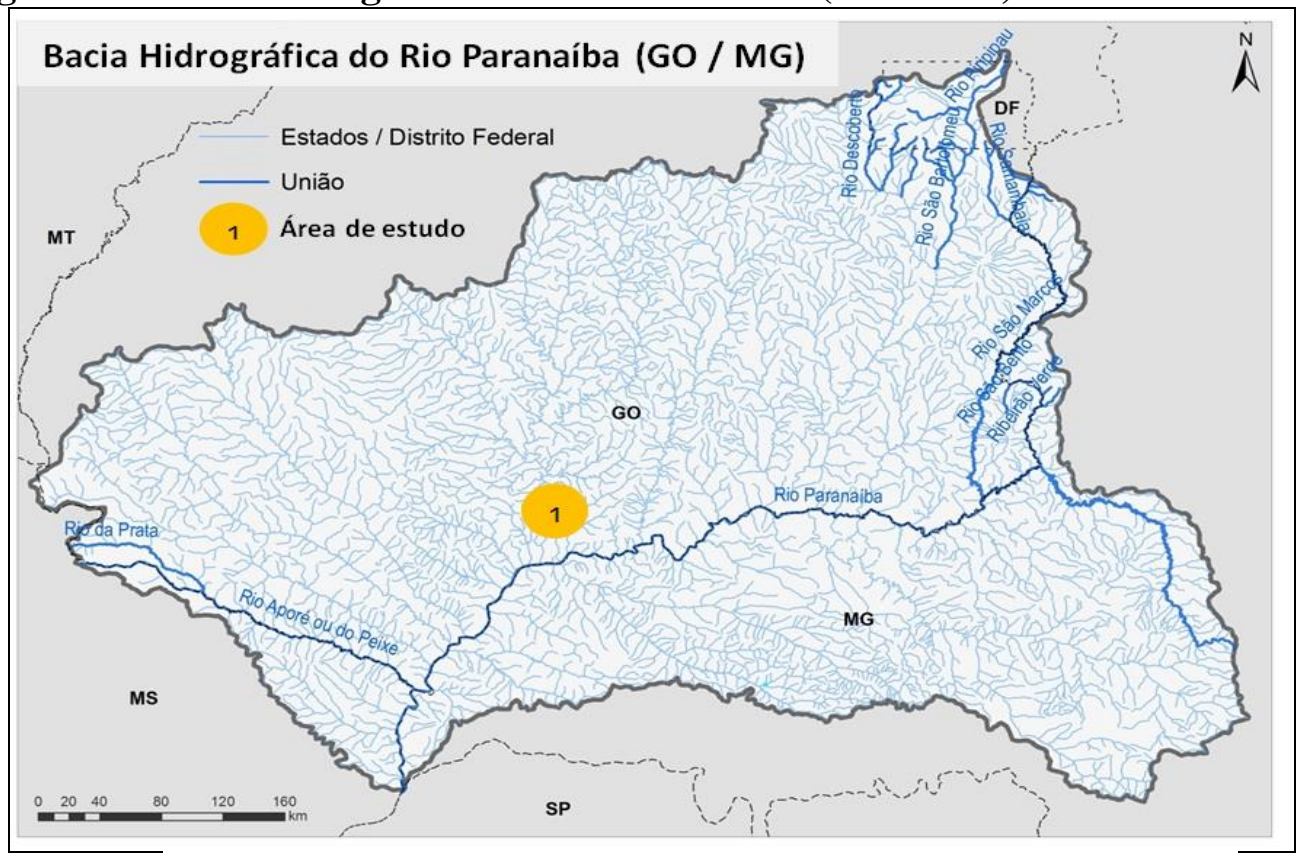

Fonte: CBH Paranaíba (2014), modificado por Vandervilson Alves Carneiro (2015).

Nesse caso, as belezas cênicas da Serra da Confusão do Rio Preto estão inseridas em paisagens sedimentares. Geologia caracterizada pela Formação Marília do Grupo Bauru, como mostra as figuras 4 e 5. Guerra (1978, p. 192), traz o conceito de Formação Sedimentar, como "depósito provindo da destruição de outras rochas tais como as eruptivas ou metamórficas".

Figura 4 - Formação Marília composta por arenitos grosseiros e materiais rudáceos (A) e (B, C) blocos conglomeráticos

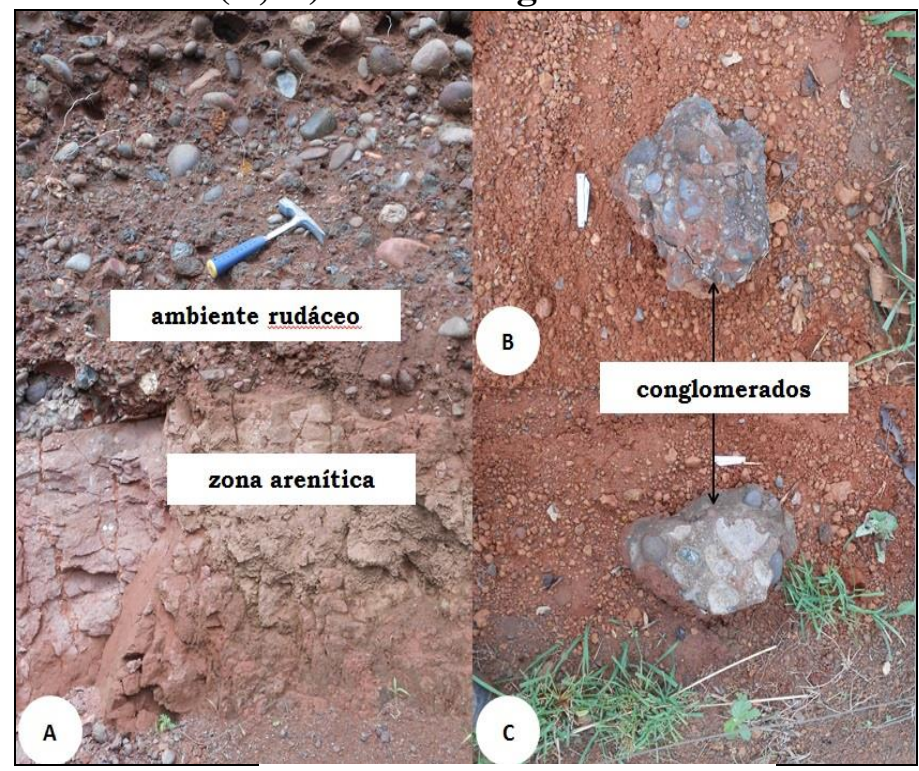

Fonte: Vandervilson Alves Carneiro (2014). 
Figura 5 - Perfil de paleossolo com concentrações de CaCO3 (porções brancas)

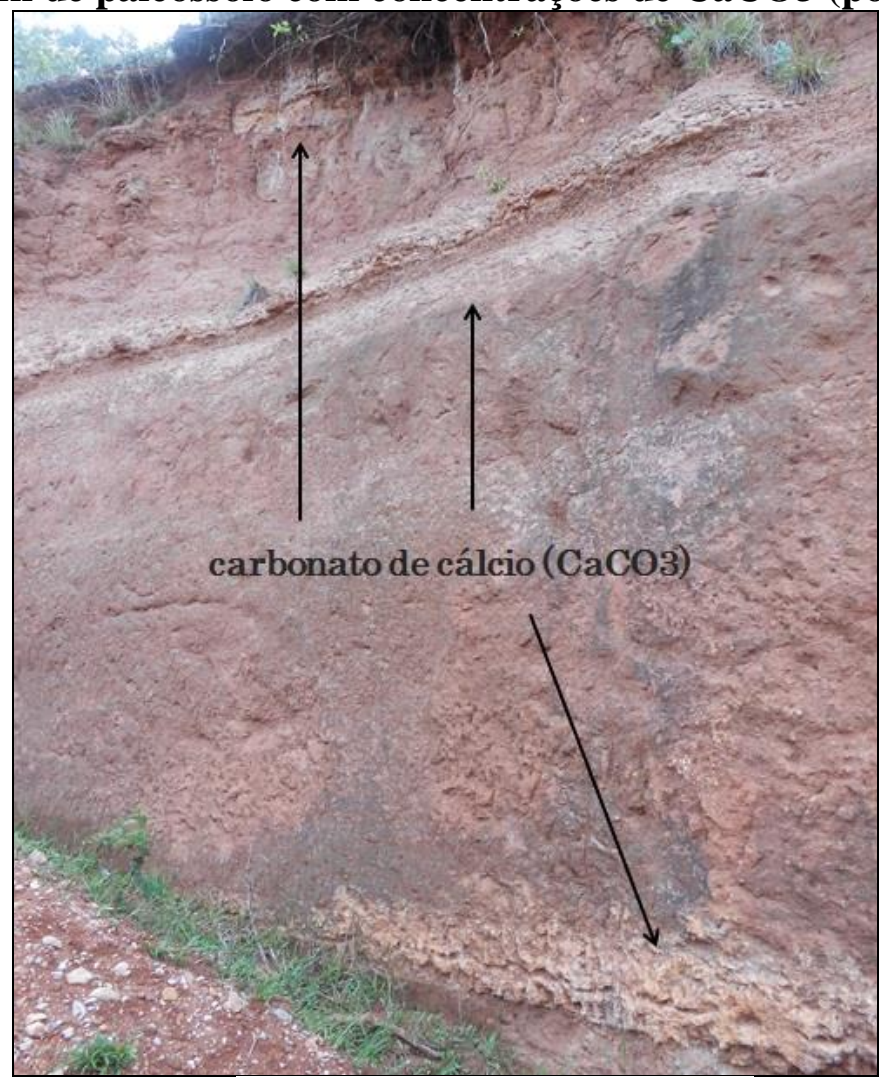

Fonte: Vandervilson Alves Carneiro (2014).

Conforme Santos (2010, p. 109-110), o Grupo Bauru é uma unidade que representa uma intensa deposição de arenitos que, de forma particularizada, ocorreu na área investigada durante o período Cretáceo, causada pelos processos geológicos de subsidência. Nessa formação geológica (rochas) que são investigados os fósseis de dinossauros.

\section{Trabalho de campo, investigações e ensinagens ${ }^{3}$ na Serra da Confusão do Rio Preto}

O trabalho de campo é um dos focos dos cursos de Licenciatura em Geografia, Licenciatura em Química e Licenciatura em Ciências Biológicas da $\mathrm{UEG}^{4}$ - Campus Quirinópolis e Campus Henrique Santillo / Anápolis, ambos no Estado de Goiás - que realizam, todo ano, vários projetos com vistas a integrar o conhecimento de sala de aula ao

\footnotetext{
${ }^{3}$ A expressão ENSINAGEM foi inicialmente explicitada no texto de ANASTASIOU, L. G. C., resultante da pesquisa de doutorado em 1998. Trata-se de um termo adotado para significar uma situação de ensino da qual necessariamente decorra a aprendizagem, sendo a parceria entre professor e alunos, condição fundamental para o enfrentamento do conhecimento, necessário à formação do aluno durante o cursar da graduação.

${ }^{4}$ Universidade Estadual de Goiás.
} 
SANTOS, J. C. V.; CARNEIRO, V. A.; PAULO, P. O.

Serra da Confusão do Rio Preto (Quirinópolis e Rio Verde, estado de Goiás): trabalho de campo, investigações e ensinagens

empírico, ciente de que é sempre uma tarefa complexa diante das diferentes dimensões e escalas territoriais que exigem alternativas para superar as inúmeras lacunas. Por essa relevância do ensino no campo, tem tornado possível estudar tanto a Geologia como a Paleontologia e encontrar alguns vestígios fósseis na região denominada Serra da Confusão do Rio Preto.

Para Carneiro (2009, p. 26) "cabe dizer, neste instante, que o trabalho de campo não é tudo e também não é uma ferramenta exclusiva da Geografia. Demais ramos do saber também utilizam deste recurso didático, como exemplos: a Antropologia, a Geologia, a Biologia, dentre outros".

Ainda enfatiza que:

[...] o trabalho de campo é benéfico e cumpre seus objetivos científicos e pedagógicos. Portanto, dizemos que ele foi utilizado para vários fins pelos povos, correntes científicas e escolas geográficas; e, cabe ao geógrafo entoar a significância dessa atividade, onde o campo é um laboratório (CARNEIRO, 2009, p. 105).

Especificamente no que concerne ao estudo geológico e paleontológico dessa paisagem constituída pelos bens naturais, em 2012, após uma pesquisa de campo foram encontrados alguns fragmentos de fósseis de dinossauros no Grupo Bauru (figura 6). As informações dessa descoberta foram publicadas no artigo BONES OUT OF THE CERRADO: NEW DINOSAUR EXPLORATORY FRONTIER IN GOIÁS STATE:

The conglomerates from the Adamantina and Marília Formations yielded some fragmentary bones, among them sauropod and theropod dinosaurs. The fragment of sauropod vertebra, a partial zygapophysis, is here associated to Titanosauriformes clade by display high density spongy pneumatic texture bone, common feature of caudal vertebra of this clade. Still being prepared are sauropod vertebra, a possible theropod claw and other elements (SANTOS et al., 2013, p. 75).

"Fóssil é um resto ou vestígio de seres orgânicos (vegetais e animais) que deixaram suas pegadas, [rastros e/ou foram sepultados, envolvidos] nas rochas da crosta terrestre" (GUERRA, 1978, p. 193). "Em Paleontología la noción de fóssil tiene um alcance muy superior, ya que com esa palabra se designa cualquier resto, molde o huella de um organismo o de su actividad biológica conservada em el sedimento" (PARDO, 1996, p. 31). Graças aos fósseis podemos identificar, por exemplo, a idade de um terreno na América do Sul, América do Norte, Europa e outras regiões do planeta, especificando sua posição na coluna geológica. 
Figura 6 - Imagens de possível fragmento fóssil

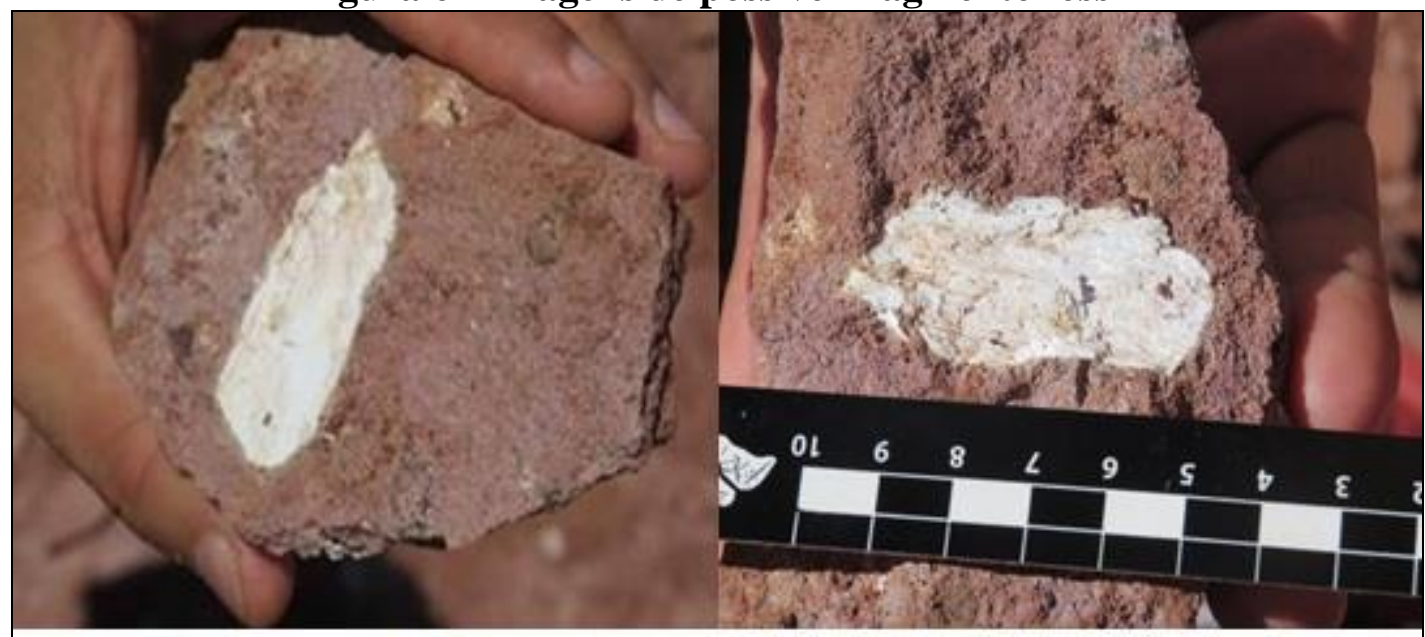

Fonte: UEG - Campus Quirinópolis, Curso de Ciências Biológicas, 2016.

Os pesquisadores Limonta e Moura (2011, p. 41-42) lembram que os fósseis são entidades paleontológicas fundamentais para o estudo da Paleontologia, nos dando informações biológicas do passado da Terra. Numa perspectiva educacional, "esta ciência cumpre o objetivo de contribuir na geração de processos do conhecimento, auxiliando na compreensão de processos naturais complexos, colaborando na formação de cidadãos críticos e atuantes dentro de uma sociedade".

A Paleontologia é a:

[...] ciência que estuda os seres vivos que existiram nos diferentes períodos da história física da Terra. [...] Graças a ela pode-se datar com segurança a idade das diferentes camadas da crosta terrestre; as mais antigas se encontram, normalmente, sob as mais recentes. Graças à paleontologia, os geólogos puderam definir e caracterizar os andares da coluna geológica. A determinação da idade dos terrenos só pode ser feita com segurança quando baseada em dados fornecidos pela paleontologia (GUERRA, 1978, p. 312).

Cabe inferir que a Paleontologia é a "ciência natural que estuda a vida do passado da Terra e o seu desenvolvimento ao longo do tempo geológico, bem como os processos de integração da informação biológica do passado no registo geológico" (SILVA, 2014, p. 88).

Nesse caso, outro objetivo dos projetos de campo é a promoção da prática interdisciplinar entre os alunos do Curso de Licenciatura em Geografia ${ }^{5}$, pois não existe a disciplina de Paleontologia na matriz curricular e demais cursos da Instituição. Infere-se então

\footnotetext{
${ }^{5}$ UEG - Campus Quirinópolis (Quirinópolis, GO)
} 

ensinagens

que o Curso de Licenciatura em Química ${ }^{6}$ não tem a disciplina Paleontologia em sua matriz, mas o conteúdo de "Fósseis" é inserido e tratado junto ao conteúdo de "Rochas Sedimentares", da disciplina de Fundamentos de Geologia. Menciona-se também que a Paleontologia é de caráter curricular do Curso de Licenciatura em Ciências Biológicas ${ }^{7}$, além de conter em sua matriz a disciplina de Geologia. Fazendo dos fósseis da paisagem cênica da Serra da Confusão do Rio Preto objeto de estudo das disciplinas de Geologia, Biogeografia, Geomorfologia, Geografia e Meio Ambiente, Paleontologia, Mineralogia, Geografia Física e Geografia do Turismo. Entretanto, não exclusivamente no Curso de Geografia do Campus da UEG/Quirinópolis, a educação em Paleontologia no Brasil encontra-se "fora dos programas curriculares escolares, onde acaba sendo abordada de maneira breve e pontual" (LIMONTA; MOURA, 2011, p. 42). Deixando de aproximar a comunidade universitária das populações locais, deixando diferentes sujeitos da base local fora do debate desta natureza.

Limonta e Moura (2011) pontuam que uma saída para contribuir com essa lacuna é a extensão universitária, onde programas educativos como exposições, cursos de campo e projetos colaboram para levar a Paleontologia a diversos segmentos da sociedade rural e urbana. É fundamental, nesse contexto, expor para moradores rurais e urbanos a importância dos estudos e pesquisas paleontológicas de base local e regional, pois:

[...] temos que investir na conscientização da população quanto a preservação e conservação deste patrimônio, ou seja, dos nossos bens naturais. Mas para proteger, a população precisa conhecer e, para isso, um dos instrumentos de aporte são as exposições e as ações educativas que podem ser desenvolvidas a partir delas (LIMONTA; MOURA, 2011, p. 43).

Afirma-se que no caso específico do patrimônio geográfico, geológico e paleontológico da Serra da Confusão do Rio Preto, ainda se faz necessário um trabalho de informação da comunidade de base local, universitária e educação básica, com participação ativa do poder público. Criando condições necessárias para o desenvolvimento da aprendizagem, das trocas entre pesquisa e ensinagens nas dezenas de propriedades rurais existentes nessa paisagem cênica do Município de Quirinópolis.

Vale destacar que esse desenvolvimento de ensinagens, levantamentos e pesquisas paleontológicas $^{8}$, devem ser realizados sob uma análise crítica de conteúdos teóricos e

\footnotetext{
${ }^{6}$ UEG - Campus Henrique Santillo (Anápolis, GO)

${ }^{7}$ UEG - Campus Henrique Santillo (Anápolis, GO)

${ }^{8}$ Levantamentos e pesquisas paleontológicas são realizados pela SEGEP - Seção de Geologia e Paleontologia (UEG - Universidade Estadual de Goiás, Campus Henrique Santillo / Anápolis - GO, pois, tem um caráter duplo:
} 
SANTOS, J. C. V.; CARNEIRO, V. A.; PAULO, P. O.

Serra da Confusão do Rio Preto (Quirinópolis e Rio Verde, estado de Goiás): trabalho de campo, investigações e ensinagens

metodológicos que se apoiam nas geografias da sociedade e natureza. Porque os materiais encontrados, artigos científicos, livros e textos utilizados como suportes aos trabalhos de campo são responsáveis por sedimentar os debates interdisciplinares que envolvem conceitos, temas e conteúdos das ciências geográfica, geológica e paleontológica em sala de aula.

Nesse prisma é importante oferecer atividades que proporcionam aos discentes, em conjunto com professores, discutir conteúdos como a Paleontologia e o desenvolvimento de base local; a questão agrária da pequena propriedade e o impacto da cultura canavieira no modo de vida rural e potencialidades geológicas e geomorfológicas; a economia dos lugares; os impactos ambientais e os reflexos sobre os sítios paleontológicos dos municípios de Quirinópolis e de Rio Verde; o potencial fóssil como atrativo para o desenvolvimento do turismo na Serra da Confusão do Rio Preto; e a educação no campo.

Porém, somada as especificidades aqui apresentadas, são notórias as dificuldades enfrentadas por professores e pesquisadores nessa região do Cerrado Goiano, e entre os fatores que dificultam o desenvolvimento das pesquisas paleontológicas, estão “[...] a pequena intensidade de tentativas de prospecção (coleta). Outro fator é a dificuldade de encontrar afloramentos passíveis de escavações" (CANDEIRO et al., 2011, p. 33). A área com maior intensidade de estratos pesquisados no Município de Quirinópolis é pertencente ao Grupo Bauru, composto pela Formação Marília.

A promoção de qualidade de vida aos moradores e pesquisadores passa pela conservação dos recursos naturais a partir de práticas adequadas das atividades de ensino nos lugares, contrapondo-se ao método devastador da natureza ocorrido pelos avanços tecnológicos, aliados a uma monocultura agrícola mal planejada nos últimos anos nas regiões de Cerrado do interior do Brasil.

Consequentemente espera-se que esses fósseis e a geodiversidade possam sensibilizar empreendedores rurais e poder público local sobre a importância de se investir na atividade de turismo educativo, construindo hotéis/pousadas rurais e museus paleontológicos; por conseguinte, será possível usufruir e valorizar essa beleza cênica regional.

1) espaço formal de ensino e pesquisa e 2) ambiente não formal (onde pode ser apreciada uma exposição que aborde os aspectos relativos à Geologia, à Paleontologia, à Geografia e de grande relevância para a atividade do turismo local). Bem como em exposições itinerantes em escolas públicas de Quirinópolis e também em pequenas exposições permanentes nas referidas fazendas. 


\section{O turismo rural na Serra da Confusão do Rio Preto e adjacências}

Compreender o turismo no espaço rural da Serra da Confusão do Rio Preto e seu entorno, requer afirmar que outras lógicas econômicas são possíveis, não anulando as lógicas agropecuárias tradicionais e modernas existentes nessa paisagem. Pois alguns proprietários têm-se mostrado interessados em abrir suas propriedades para o turismo, visando garantir uma sobrerrenda a criação de gado e até mesmo ao cultivo da cana-de-açúcar e soja. Buscando valorizar uma existência rural cheia de particularidades e substâncias, com elementos relacionados ao espaço e tempo de existência dos sujeitos do lugar.

$\mathrm{Na}$ paisagem pesquisada é possível encontrar atrativos próximos, em que o visitante percorre no máximo 15 quilômetros de distância entre os atrativos Vale do Cedro, Fazenda Cabeleira e Engenho Urbano localizado no Distrito de Riverlândia ${ }^{9}$, Município de Rio Verde. Esses empreendimentos têm possibilitado o turismo rural na Serra da Confusão do Rio Preto e seu entorno, proporcionando uma tipologia turística e um rearranjo na configuração produtiva, principalmente na Fazenda Cabeleira (figuras 7 e 8).

Essa propriedade, ou seja, a Fazenda Cabeleira disponibiliza hospedagens, refeições e diversas atividades de lazer aos visitantes que chegam ao lugar, no entanto, podese dizer que o trabalho de divulgação é pequeno e a sinalização turística inexistente, visto que faltam parcerias e apoio do poder público. Essas novas modificações têm gerado um desenvolvimento lento, porém, se colocam como uma alternativa econômica aos proprietários do Engenho Urbano, Fazenda Cabeleira e assentados do INCRA (Instituto Nacional de Colonização e Reforma Agrária) no Vale do Cedro, potencializando na região um destino de visitação.

Com sua cachoeira no Córrego Cabeleira e presença de vegetação de Cerrado, o Vale do Cedro é considerado uma especificidade do lugar, possuindo uma beleza e exuberância cênica, responsável por atrair turistas ao entorno da Serra da Confusão do Rio Preto. No entanto, essa paisagem não pode ser concebida apenas pelos elementos físicos, mas também pelas relações sociais e culturais de sujeitos locais.

\footnotetext{
${ }^{9}$ O Distrito de Riverlândia está localizado a 70 quilômetros da cidade de Rio Verde (Sede) e a 40 quilômetros da cidade de Quirinópolis, no Estado de Goiás, na bacia do Córrego Cabeleira.
} 
Serra da Confusão do Rio Preto (Quirinópolis e Rio Verde, estado de Goiás): trabalho de campo, investigações e ensinagens

Figura 7 - Cenários na Serra da Confusão do Rio Preto: (A) Vista da serra com atividade rural na circunvizinhança, (B) Cachoeira do Córrego Cabeleira no Vale do Cedro, (C) Vista da Fazenda Cabeleira e (D) Sede da Fazenda Cabeleira

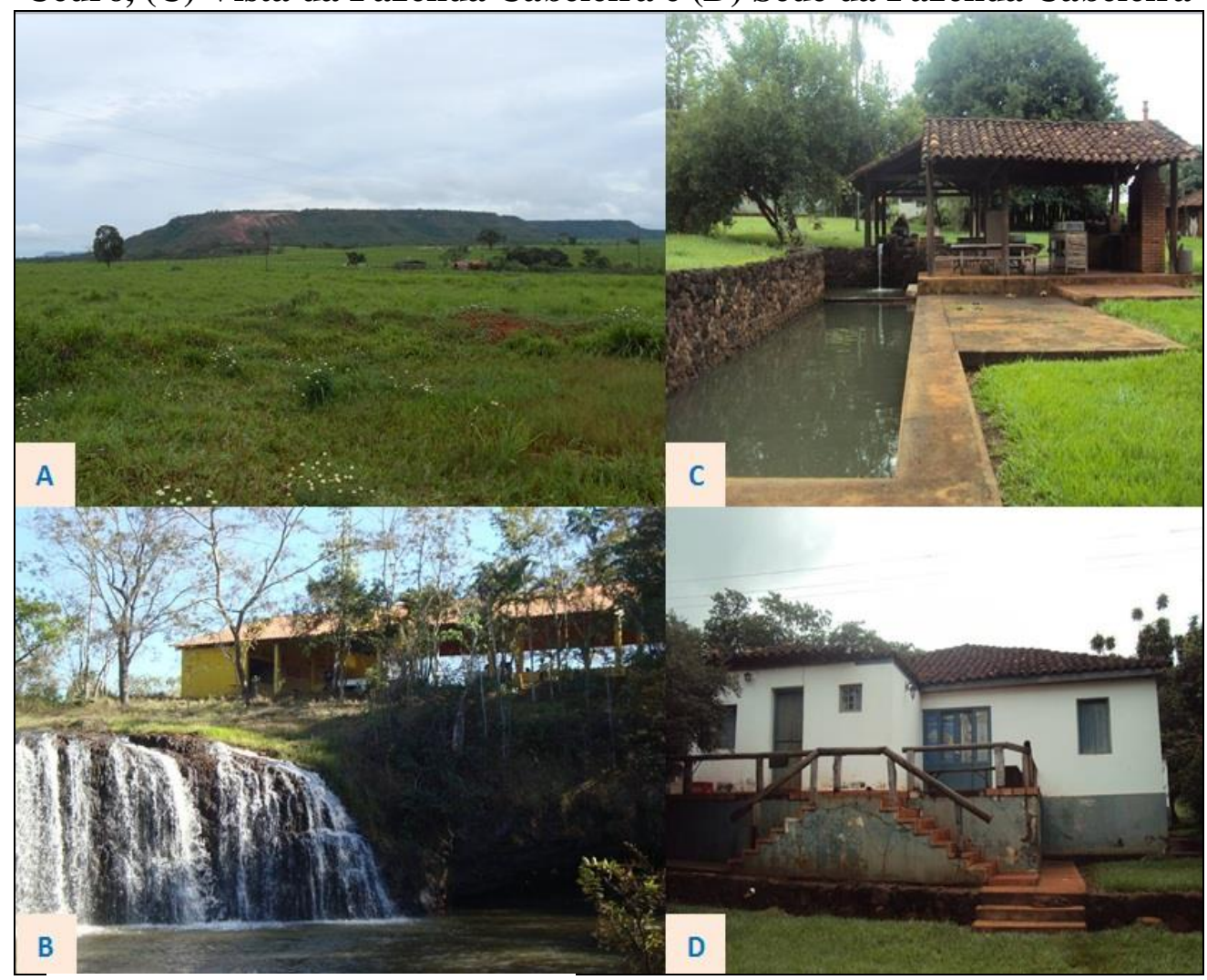

Fonte: (A) Vandervilson Alves Carneiro (2014), (B) Jean Carlos Vieira Santos (2013), (C e D) Débora Cristina Barbosa da Silva (2013).

Figura 8 - Cachoeira no Córrego Cabeleira em domínio basáltico

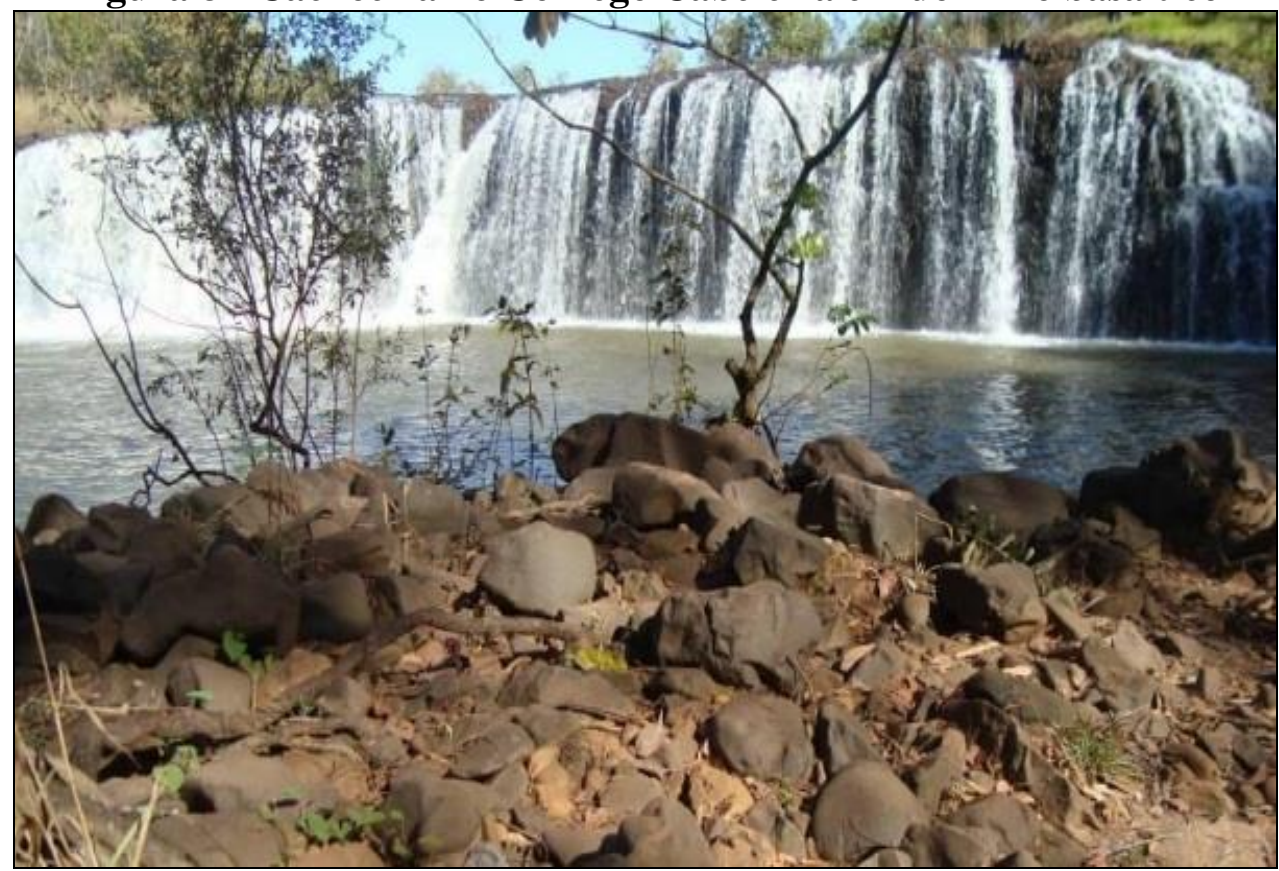

Fonte: Jean Carlos Vieira Santos (2014). 
Cabe dizer que essa comunidade identifica-se com atividade de lazer ali desenvolvida, fazendo parte do cotidiano e apresentando as quedas d'água como um elemento identitário forte do lugar. O turismo e o lazer vêm despontando como uma nova realidade que, embora ainda incipiente, começa a chamar a atenção de proprietários e atores locais sensibilizados com essas atividades.

Nota-se que esse turismo e lazer, na zona rural, devem ser concebidos ainda como uma atividade de pequena escala, artesanal, que se bem planejado deverá propiciar um incremento na qualidade de vida dos moradores locais, tornando uma função muito importante no âmbito do desenvolvimento social, econômico e cultural de base local.

Com a chegada do turismo rural à região tem proporcionado à comunidade, uma expectativa de desenvolvimento local com a continuidade de práticas sociais de sujeitos que mantêm seus modos de vida num território tensionado pelo agronegócio, principalmente pelo fato de manterem estratégias e arranjos produtivos e culturais que tem garantido a permanência no lugar.

\section{Espaço rural da Serra da Confusão do Rio Preto: Potencialidade turística e espaços vazios de infraestrutura de acolhimento de turistas}

Embora seja possível afirmar que as práticas de visitação aos espaços rurais dos municípios de Quirinópolis e Rio Verde, com suas fazendas, pesque-pagues e demais infraestruturas de lazer já possui um significado na paisagem regional, é relevante lembrar que temos também nesses territórios um fazer turístico "sem um compromisso maior" (MÜLLER, 2002, p. 09). Neste sentido, cada reflexão pode adotar o discurso que esses lugares são menos significativos que aqueles inventados pelo turismo.

O dito acima, caminha numa direção de propor neste artigo um estudo de identificação dos atrativos potenciais dos espaços rurais na Serra da Confusão do Rio Preto em que as atividades ligadas ao turismo rural não se fazem presentes. Essa acepção ainda que simplista represente uma importante reflexão que permitirá conhecer a sociedade rural que historicamente vem construindo seus modos de vida, situado para além da perspectiva do agronegócio predominante na região.

Esse ambiente com potencialidades diversas permite encontrar proprietários locais animados em implantar e desenvolver a atividade turística, podendo destacar os atores das Fazendas Recanto da Serra e Furnas da Serra (Quirinópolis), que vêem o turismo como uma 
SANTOS, J. C. V.; CARNEIRO, V. A.; PAULO, P. O.

Serra da Confusão do Rio Preto (Quirinópolis e Rio Verde, estado de Goiás): trabalho de campo, investigações e ensinagens

alternativa de ampliação da renda familiar. Desse modo é importante promover debates e apresentar os recursos naturais, sociais e culturais de base local, apresentando indicadores potenciais a própria comunidade.

\section{A Serra da Confusão do Rio Preto e seus recursos naturais}

Segundo o prisma geográfico o objeto de investigação deste artigo, os municípios de Quirinópolis e Rio Verde, estão localizados na Região Sudoeste Goiano, conforme croqui disponibilizado pelo $\mathrm{IMB}^{10}$ em 2006 (figura 9). Segundo Santos (2010), a Serra da Confusão do Rio Preto, limite geográfico entre as duas municipalidades, pertence geologicamente ao Grupo Bauru e apesar de possuir grande beleza cênica:

[...] é pouco representativa ao longo da região estudada, com ocorrências restritas a alguns divisores de água, nas proximidades de cidades como Quirinópolis, Rio Verde, Caçu, Itarumã e Cachoeira Alta. Esses sedimentos do período Cretáceo Superior caracterizam-se por apresentar um relevo movimentado, com feições residuais típicas apresentando escarpas abruptas. O contato da Formação Marília com a Formação Adamantina (Grupo Bauru) se faz de forma gradacional. São formas que chamam atenção da população local, por sua beleza e destaque na paisagem regional, sendo utilizadas para práticas de trilhas e observações dos lugares. Estão presentes ali várias cachoeiras (SANTOS, 2010, p. 110).

Portanto, essa paisagem serrana é uma particularidade do lugar investigado, formando uma beleza e exuberância cênica associada ao Bioma Cerrado, e juntos agregam valor e desperta o interesse dos visitantes que chegam a esse espaço rural. Nascimento, Ruschkys e Mantesso-Neto (2008, p. 8-9) destacam que o "turismo (modalidade geoturismo) nestas áreas pode funcionar como opção de lazer, educação, recreação e contemplação da beleza cênica, além de promover a divulgação, preservação e conservação de forma eficiente e interessante".

Corroborando com Medina e Santamarina (2004, p. 61), pode-se dizer que essa serra com sua geologia e geomorfologia são belezas cênicas consideradas patrimônios naturais, pois são “[..] formaciones físicas, biológicas y geológicas xtraordinárias”. Consequentemente, essa beleza poderá sensibilizar os empreendedores e poder público local sobre a importância de investir na atividade turística, incentivando a construção de hotéis/pousadas rurais. Procurando usufruir dessa beleza cênica regional.

\footnotetext{
${ }^{10}$ Instituto Mauro Borges de Estatísticas e Estudos Socioeconômicos
} 


\section{ESTADO DE GOIÁS Regiões de Planejamento}

\section{Região Sudoeste Goiano}

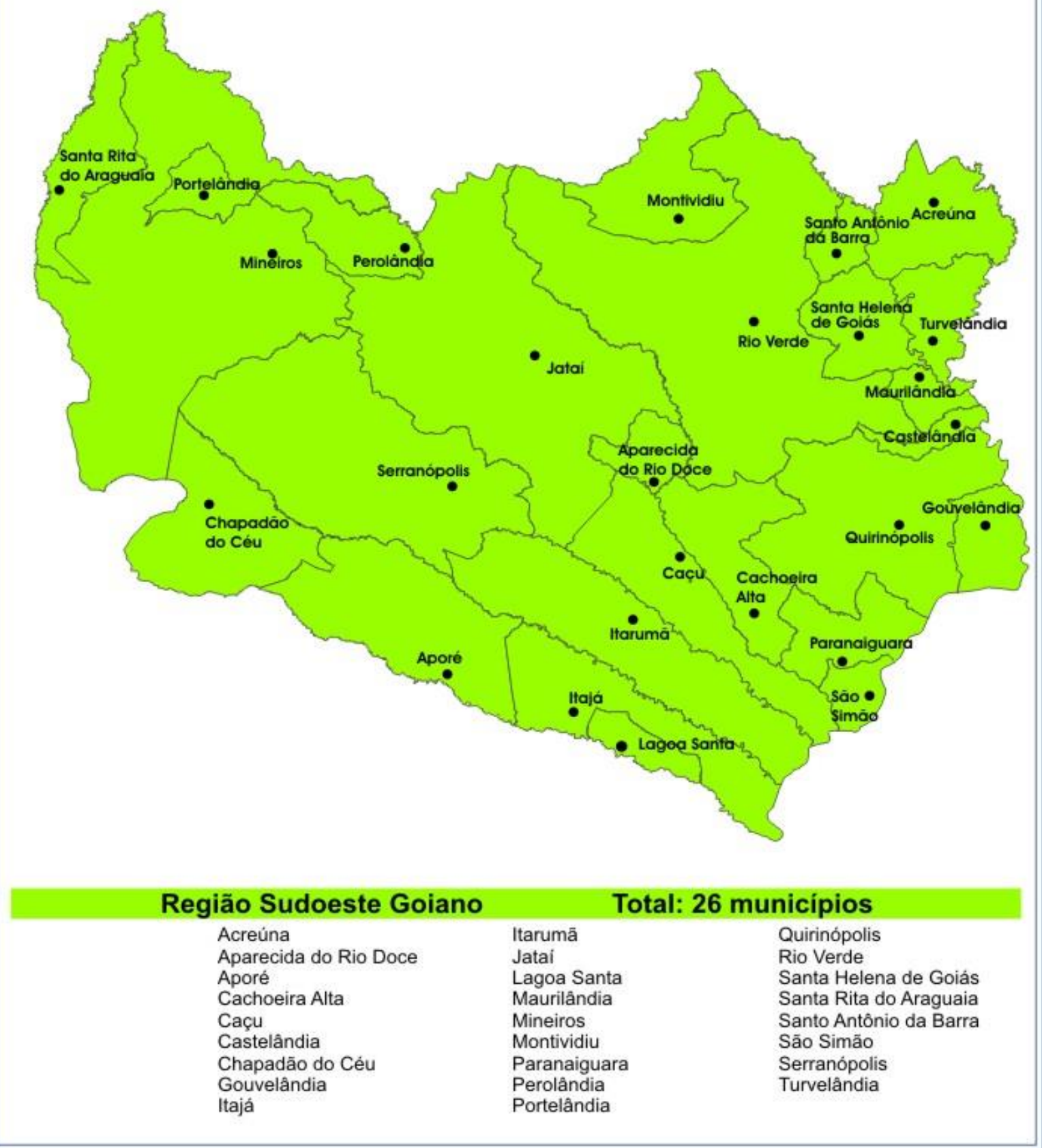

Fonte: IMB, 2006. 
Faz-se necessário que os poderes públicos tanto de Quirinópolis como de Rio Verde realizem ações de apoio às trilhas ecológicas já praticadas por moradores na região serrana, favorecida pela proximidade com a zona urbana de Quirinópolis e de outros povoados como Ouroana e Riverlândia. Nesse percurso informal, os visitantes têm contato com os conteúdos de ruralidade e memórias de antigas fazendas como Engenho da Serra e Confusão do Rio Preto, e com a geodiverdidade (cachoeiras, geologias, relevos etc.), biodiversidade do Cerrado, especialmente na Comunidade Rural de Salgado.

Com relação à geodiversidade, Silva (2008) diz que são os estudos destinados à preservação do patrimônio natural, tais como monumentos geológicos, paisagens naturais, sítios paleontológicos etc.

Nessa contextualização dos recursos naturais, é preciso que as atividades econômicas e grupos sociais regionais não se anulem, mas que estes grupos possam se articular de diversas formas e, sobretudo baseado naquilo que é de interesse comum, realizando-se a partir das práticas diversas dos lugares, formando um roteiro turístico rural potencializado pelos recursos naturais, sociais e culturais.

\section{A Serra da Confusão do Rio Preto e seus recursos sociais e culturais}

Nesse foco geográfico em relação à estética da natureza local, Santos (2010) assinala que com os recursos encontrados no Bioma Cerrado, os tradicionais habitantes da Serra da Confusão do Rio Preto foram criando nos lugares uma cultura própria, com hábitos alimentares e modos de vida próprios das populações do interior de Goiás, densidades que hoje se fazem presentes nos festivais gastronômicos, festas religiosas e agropecuárias, residências urbanas e rurais, feiras, bares e restaurantes dos municípios de Quirinópolis e de Rio Verde.

Em sua obra, Bourdin (2001) destaca que o homem se define e se constrói por meio do conhecimento de seu entorno imediato, que é ao mesmo tempo material e social, criando o grupo de pertença, onde ambos são indissociáveis. O conhecimento que dele temos se exprime e se organiza na representação do território, mas esse só pode ser o território próximo se atuamos ou nos identificamos com ele.

Uma perspectiva considerável que se torna extensivo aos espaços rurais dos municípios investigados, onde se desenvolvem vínculos, relações de entretenimento e lazer a partir da vida cotidiana, mesmo não incorporando a discussão de que essa possa ser uma 
SANTOS, J. C. V.; CARNEIRO, V. A.; PAULO, P. O.

Serra da Confusão do Rio Preto (Quirinópolis e Rio Verde, estado de Goiás): trabalho de campo, investigações e ensinagens

lógica de desenvolvimento do turismo no espaço rural, "[...] uma invenção de citadinos que vão ao campo descobrir o que eles não conhecem" (ALMEIDA, 2003, p.18).

Dentre as potencialidades culturais e sociais da Serra Confusão do Rio Preto está à arte de cozinhar. Nas propriedades rurais é possível encontrar receitas interessantes e até inusitadas que fazem parte do gosto popular regional. São alimentos que cotidianamente estão na mesa de cozinhas rurais, podendo destacar: o arroz com carnes de galinha, de bovinos e suínos, o pequi que é um fruto nativo do Cerrado, as farinhas de mandioca e milho, as pamonhas e a chica doida ${ }^{11}$, doces e uma diversidade de biscoitos.

Percebe-se também que no interior das residências, dessa zona rural, ainda é facilmente encontrado peças artesanais oleiras, mostrando profundas marcas da memória e identidade que permanecem integrados ao sistema cultural do lugar. Este entendimento pode respaldar-se em Pla (2006, p. 08) que destaca o artesanato como uma expressão primordial, original e "también, y basicamente, servício. [...] como receptáculo de valores estéticos y socio-culturales, y que tiene su índice en la creciente adquisición de objetos artesanales que enriquecen, artística o utilitariamente, la vida cotidiana”. Para Castro e Santos (2005, p. 09), "En las diferentes culturas del mundo la cerámica se pone de manifesto a lo largo de la historia [...]". São elementos que permitem compreender os sentimentos e ações dos moradores locais.

Portanto, essas práticas espaciais e esses saberes se realizam nessa paisagem, apresentando um patrimônio edificado rural caracterizado por construções que agregam as funções essenciais de convivência em sociedade. São imóveis que permanecem nos territórios de serra em Goiás, com significados profundos por possuírem a força de revelar a história do processo construtivo, dos modos de morar e de apropriar-se do espaço, característicos do lugar onde se insere.

Nesse prumo, o patrimônio edificado rural passa ser um bem cultural, formando parte do patrimônio comunitário, e, às vezes, tendo significados para uma população maior, expandindo sua abrangência para além do local, tornando-se um atrativo turístico da propriedade. O patrimônio edificado, portanto, orienta a população para a qual representa significados simbólicos, revelando sua história e sendo depositário da identidade do grupo social local ou regional (SANTOS; ALVES, 2005). Face aos exemplos já citados, convém

\footnotetext{
${ }^{11}$ Prato típico da região do sudoeste goiano à base de milho com presença de linguiça de porco, banha de porco, queijo, jiló e temperos à vontade.
} 
destacar, mesmo repetindo, o patrimônio edificado da Fazenda Cabeleira que é uma autenticidade material do Cerrado.

Nessa região, os elementos materiais e imateriais aparecem relacionados às práticas socioculturais, são instrumentos, ferramentas e utensílios que também "retratam o modo de vida camponês" (SOUZA, 2013, p.48). Os instrumentos de trabalho e utensílios mais antigos, além da forma e função, caracterizam representações sociais de outros tempos. Entre esses elementos estão: a roda d'água, moinhos de café, carro de boi, fogão a lenha, lamparinas, monjolos e currais de madeira.

Entre os simbolismos encontrados estão os cruzeiros, cabeças e chifres de boi e imagens de santos católicos que compõem o patrimônio imaterial, principalmente, nas pequenas propriedades rurais. Esses estão fortemente ligados às práticas sociais que criaram identidades das comunidades desta parte do cerrado. As várias cabeças e chifres de bovinos e equinos que são esqueletos colocados na frente das casas e jardins e em porteiras de fazendas. Segundo as falas de moradores, é uma forma de expulsar "quebrantos, urucubacas e invejas" e manter ou trazer fartura para as propriedades que ficam protegidas.

Nessas propriedades rurais de base familiar, as estruturas de organização relacionam-se às instituições presentes no cotidiano da comunidade: a família, a religião, e a lida diária com a terra e animais. No entanto, essas estruturas não evitam mudanças no comportamento econômico rural, pelo contrário, esse sistema é sempre priorizado pelas famílias.

Enfim, o que existe nessa paisagem é um sistema de atrativos que podem proporcionar a criação de um destino rural, um receptivo de base local que alimentará a prática da atividade turística associada ao lazer e entretenimento em evidência no cenário nacional, especialmente nas primeiras décadas do século XXI.

\section{CONSIDERAÇÕES FINAIS}

Torna-se evidente tanto o incentivo governamental, a implementação infraestrutural, o apoio para uma mão de obra qualificada como o investimento em novos empreendimentos turísticos em domínio rural e que possibilitem um (re) arranjo na 
SANTOS, J. C. V.; CARNEIRO, V. A.; PAULO, P. O.

Serra da Confusão do Rio Preto (Quirinópolis e Rio Verde, estado de Goiás): trabalho de campo, investigações e ensinagens

configuração produtiva das propriedades na Serra da Confusão do Rio Preto e circunvizinhança.

Esse espaço rural tradicionalmente tem atividades agropecuárias como alicerce econômico principal, contudo, entre as atividades produtivas desenvolvidas no local, o turismo e o lazer poderão despontar como uma nova lógica, visto que atores locais se mostram motivados em vivenciar essa experiência, alimentada pelo novo no lugar.

O ambiente estudado da Serra da Confusão do Rio Preto tem por viga-mestra o turismo rural como uma atividade de pequena escala, artesanal, fomentando e incrementando uma qualidade de vida para os moradores locais e valorizando o vínculo com o território geográfico. O turismo rural carece de políticas públicas que sensibilizem atores e empreendedores que estão dispostos a investir nessa vertente econômica.

O trabalho de campo e o olhar geográfico propiciaram compreender o espaço rural da Serra da Confusão do Rio Preto em seus pormenores, reentrâncias, densidades e, concomitantemente, um cenário paisagístico em que se desenvolve a vida em todas as suas dimensões, à medida que os usos, práticas e apropriações vão se definindo no espaço pelas mãos humanas e assim fixando seus movimentos sociais pretéritos e contemporâneos.

Esse detalhamento realizado in loco permitiu a identificação de processos históricos, sociais, naturais e culturais que dão possibilidades de efetivação do turismo no ambiente rural, mediante o aproveitamento de recursos autóctones, favorecendo o fortalecimento econômico, social e cultural das comunidades e de pequenas e médias propriedades rurais. Assim, infere-se que o arcabouço teórico e a experiência empírica nos conduziram a entender que as políticas públicas direcionadas ao turismo rural terão que ser aplicadas e propostas a partir daquilo que já existem nos lugarejos.

Nos rincões do território brasileiro, os lugarejos não se reproduzem turisticamente sozinhos, porque não são autossuficientes para aquilo que demanda o turismo. Assim, a demanda dos lugarejos potencializados a desenvolver um turismo de cunho rural deve ser engendrada em âmbito regional. Valorizando os conteúdos sociais e naturais da interioridade, elegendo o saber e fazer regional e as substancias socioculturais de uma ruralidade presente no artesanato, na culinária, nas festas e nas diversas manifestações da cultura popular.

No ambiente cerradeiro, é possível encontrar diversas formas das populações tradicionais se apresentarem enquanto sujeitos que expressam processos envolvendo sistemas produtivos e modos de vida, mesmo que estejam sendo capturados pela produção dominante. 
Nessas paisagens rurais do Cerrado, onde a fé religiosa se manifesta nas festas das padroeiras e novenários, num misto de religioso com o profano, a diversidade cultural ecoa nos cantos e se materializa nos produtos artesanais locais. Em outras palavras, esses palcos do interior são conjuntos de lugares com expressões da singularidade de seus habitantes com valores culturais relacionados a esses grupos sociais tradicionais que habitam as áreas de Cerrado, como no caso da Serra da Confusão do Rio Preto e adjacências.

Cabe ressaltar que esses ambientes, o caso da Serra da Confusão do Rio Preto, são ricos em geodiversidade e em outras temáticas que podem compor projetos educacionais formais e não formais. Também propiciam pesquisas, trabalhos de campo, aprendizagens, ensinagens e desvelamentos.

\section{REFERÊNCIAS}

AGÊNCIA GOIANA DO MEIO AMBIENTE - AGMA. Estudo Integrado de Bacias Hidrográficas para Avaliação de Aproveitamento Hidrelétrico (EIBH) da região sudoeste goiana. Caçu: Mais Verde / Engevix, 2005.

AGUIAR, L. M. S.; CAMARGO, A. J. A. Cerrado: ecologia e caracterização. Brasília: Embrapa, 2004.

ALMEIDA, M. G. Lugares turísticos e a falácia do intercâmbio cultural. In: ALMEIDA, M. G. Paradigmas do turismo. Goiânia: Alternativa, 2003. p. 11-19.

ANASTASIOU, L. G. C. Metodologia do ensino superior: da prática docente a uma possível teoria pedagógica. Curitiba: IBPEX, 1998.

BOURDIN, Alain. A questão local. Rio de Janeiro: DP\&A, 2001.

CANDEIRO, C. R. A.; RANGEL, C. C.; CASTANHO, R. B.; CASTILHO, L. H.; BLANCO, J.; PEREIRA, C. T.; ALVES, D. S. J. In: CANDEIRO, C. R. A. (Org.). No alvorecer da exposição - dinossauros e fósseis do Triângulo Mineiro. Rio de Janeiro: Letra Capital, 2011. p. 33-40.

CARNEIRO, V. A. Concepções de trabalho de campo e ensino de Geografia nas licenciaturas do Sudeste Goiano. 2009. 272 f. Dissertação (Mestrado em Geografia) Programa de Pós-Graduação em Geografia, Universidade Federal de Goiás, Goiânia, 2009.

CASTRO, I. A. F.; SANTOS, I. U. RAQCHI - cerâmica pre-hispanica y contemporanea. Cusco: Graficolors, 2005. 
SANTOS, J. C. V.; CARNEIRO, V. A.; PAULO, P. O.

Serra da Confusão do Rio Preto (Quirinópolis e Rio Verde, estado de Goiás): trabalho de campo, investigações e ensinagens

COMITÊ DA BACIA HIDROGRÁFICA DO RIO PARANAÍBA. Domínio dos corpos

hídricos superficiais. Itumbiara: CBH Paranaíba, 2014. Disponível em:

http://www.cbhparanaiba.org.br/galeria-de-mapas. Acesso em: 27 set. 2015.

COUTINHO, L. M. O conceito de bioma. Acta Botanica Brasilica, Belo Horizonte, v. 20, n. 1, p. 13-23, 2006. Disponível em: <http://www.scielo.br/pdf/abb/v20n1/02.pdf>. Acesso em: 27 set. 2015.

DOWLING, R. K. Geotourism's contribution to local and regional development. In: NETO DE CARVALHO C., RODRIGUES J. C. (eds.). Geoturismo \& desenvolvimento local. Idanha-a-Nova (Portugal): Câmara Municipal de Idanha-a-Nova, 2009, p.15-37.

FLAUZINO, F. S.; SILVA, M. K. A.; NISHIYAMA, L.; ROSA, R. Geotecnologia aplicada à gestão dos recursos naturais da bacia hidrográfica do Rio Paranaíba, no cerrado mineiro.

Revista Sociedade \& Natureza, Uberlândia, n. 22, abr. 2010.

GUERRA, A. T. Dicionário geológico-geomorfológico. Rio de Janeiro: IBGE, 1978.

INSTITUTO MAURO BORGES DE ESTATÍSTICAS E ESTUDOS SOCIOECONÔMICOS - IMB. Regiões de Planejamento do Estado de Goiás - 2006: Região Sudoeste Goiano. Goiânia: IMB, 2006.

INSTITUTO CERRADO E SOCIEDADE. O grau de proteção do Cerrado. Brasília: ICS, 2011. Disponível em: <http://institutocerradoesociedade.blogspot.com.br/2011/11/o-grau-deprotecao-do-cerrado.html>. Acesso em: 27 set. 2015.

KLINK, C. A.; MACHADO, R. B. A conservação do cerrado brasileiro. Megadiversidade, Rio de Janeiro, v. 1, n. 1, jul. 2005. Disponível em: <http://www.agencia.cnptia.embrapa.br/recursos/Texto_Adicional_ConservacaoIDxNOKMLsupY.pdf>. Acesso em: 27 set. 2015.

LEAL, C. R. A. A.; MARQUES, T. B. Perspectiva de desenvolvimento no Sudoeste Goiano. In: ENCONTRO NACIONAL DE GEOGRAFIA AGRÁRIA, 19, 2009, São Paulo. Anais... São Paulo: ENGA, 2009, p. 01-22.

LIMONTA, F. S.; MOURA, G. G. In: CANDEIRO, C. R. A. (Org.). No alvorecer da exposição - dinossauros e fósseis do Triângulo Mineiro. Rio de Janeiro: Letra Capital, 2011. p. 41-44.

MEDINA, N.; SANTAMARINA, J. Turismo de naturaleza en Cuba. Havana: Unión, 2004.

MULLER, A. Lazer, desenvolvimento regional: como pode nascer e se desenvolver uma ideia. In: MÜLLER, A.; DACOSTA, L. P. (Org.). Lazer e desenvolvimento regional. Santa Cruz do Sul: EdUNISC, 2002. p. 09-40.

NASCIMENTO, M. A. L.; RUCHKYS, U. A.; MANTESSO-NETO, V. Geodiversidade, geoconservação e geoturismo: trinômio importante para a proteção do patrimônio geológico. Natal: UFRN, 2008. 
NASCIMENTO, M. A. L. S. Geomorfologia do Estado de Goiás. Boletim Goiano de Geografia. Goiânia: v. 12, n. 1, jan./dez. 1991. Disponível em: $<$ https://observatoriogeogoias.iesa.ufg.br/up/215/o/NASCIMENTO_Maria_Amelia_Leite_Ge omorfologia_Go.pdf >. Acesso em: 27 set. 2015.

PARDO, A. Fosiles y fosilizacion: procesos y resultados de la larga história subterranea. Boletín SEA - Sociedad Entomológica Aragonesa, Zaragoza, n. 16, p. 31-42, 1996. Disponível em: <http://www.sea-entomologia.org/PDF/BOLETIN_16/B16-004-031.pdf〉. Acesso em: 27 set. 2015.

PEDROSO, I. L. P. B. Meio ambiente, agroindústria e ocupação dos cerrados: o caso do Município de Rio Verde no Sudoeste de Goiás. Revista Urutágua, Maringá, n. 6, 2006. 12 p.

PLA, J. La cerâmica popular paraguaya. Asunción: Universidad Católica de Nuestra Señora de la Asunción, 2006.

ROSS, J. L. S. Relevo brasileiro: uma nova proposta de classificação. Revista do Departamento de Geografia - FFLCH - USP, São Paulo, v. 4, p. 25-39, 1985. Disponível em: <http://www.revistas.usp.br/rdg/issue/view/3916>. Acesso em: 27 set. 2015.

SANTOS, J. C. V. Políticas de regionalização e criação de destinos turísticos entre o lago de São Simão e a Lagoa Santa no Baixo Paranaíba Goiano. 2010. 367 f. Tese (Doutorado em Geografia) - Instituto de Geografia, Universidade Federal de Uberlândia, Uberlândia, 2010 .

SANTOS, J. C. V. Região e destino turístico: sujeitos sensibilizados na geografia dos lugares. São Paulo: Allprint, 2013.

SANTOS, J. C. V.; RESENDE, I. L. M.; LOPES, W. H.; SARGES, R. R.; SIMBRAS, F. M.; SOUZA, L. C. A.; MACHADO, A.; ALVES, M. C.; MUNIZ, F. Bones out of the cerrado: new dinosaur exploratory frontier in Goiás State. In: BRAZILIAN DINOSAUR SYMPOSIUM, 1, 2013, Ituiutaba. Anais... Ituiutaba: UFU - Campus Pontal, n. 1, v. 1, abr. 2013.

SANTOS, R. J.; ALVES, K. B. Registro do patrimônio cultural e edificado das áreas diretamente afetadas, de entorno e influência das usinas hidrelétricas de Capim Branco I e II. Uberlândia: Composer, 2005.

SANTOS, J. C. V.; MOTA, R. D.; SANTOS, R. J. Considerações sobre algumas políticas públicas de turismo e sustentabilidade regional: o caso da Microrregião de Quirinópolis - GO. Revista Percurso, Maringá, v. 2, n. 1, p. 93-106, 2010.

SILVA, C. M. Breve glossário etimológico paleontológico. Lisboa: Universidade de Lisboa - Faculdade de Ciências - Departamento de Geologia, 2014. Disponível em:

<http://paleoviva.fc.ul.pt/Paleogeofcul/Apoio/Paleogloss.pdf>. Acesso em: 27 set. 2015. 

ensinagens

SILVA, C. R. Geodiversidade do Brasil: conhecer o passado, para entender o presente e prever o futuro. Rio de Janeiro: CPRM - SGB, 2008. Disponível em:

<http://www.cprm.gov.br/publique/media/geodiversidade_brasil.pdf $>$. Acesso em: 27 set. 2015.

SOUZA, E. A. O território e as estratégias de permanência camponesa da Comunidade Pedra Lisa no processo de expansão das lavouras de cana-de-açúcar, em Quirinópolis (GO). 2013. 351 f. Tese de (Doutorado em Geografia) - Instituto de Geografia, Universidade Federal de Uberlândia, Uberlândia, 2013.

SOUZA, E. A. Patrimônio imaterial: relações socioculturais camponesas em Pedra Lisa. Uberlândia: Composer, 2015.

\section{UNIVERSIDADE ESTADUAL DE GOIÁS. Geologia e Paleontologia no Cerrado}

Brasileiro: na busca por fósseis! Quirinópolis: UEG - Curso de Ciências Biológicas, 2016.

Disponível em:

<http://www.cienciasbiologicas.quirinopolis.ueg.br/noticia/25140_geologia_e_paleontologia_ no_cerrado_brasileiro_na_busca_por_fosseis_>. Acesso em: 06 jul. 2017.

Jean Carlos Vieira Santos - Possui Graduação, Mestrado e Doutorado em Geografia pela Universidade Federal de Uberlândia (UFU). Atualmente é Professor na Universidade Estadual de Goiás (UEG), Campus Caldas Novas.

Vandervilson Alves Carneiro - Possui Graduação em Geografia pela Universidade Estadual Paulista Júlio de Mesquita Filho (UNESP), Mestrado e Doutorado em Geografia pela Universidade Federal de Goiás (UFG). Atualmente é Professor na Universidade Estadual de Goiás (UEG), Campus Anápolis.

Pedro Oliveira Paulo - Possui Graduação em Biologia pela Pontífica Universidade Católica de Goiás (PUC/Goiás), Mestrado em Geociências e Doutorado em Geociências e Meio Ambiente, ambos cursados pela Universidade Estadual Paulista Júlio de Mesquita Filho (UNESP). Atualmente é Professor na Universidade Estadual de Goiás (UEG), Campus Anápolis.

Artigo recebido em: 27 de julho de 2017.

Artigo aceito em: 03 de setembro de 2017. 